\title{
MULTI-OBJECTIVE VEHICLE ROUTING PROBLEM WITH TIMES WINDOWS DENGAN PENDEKATAN GOAL PROGRAMMING UNTUK MENYELESAIKAN MASALAH OPTIMISASI RUTE PERJALANAN BUS PARIWISATA
}

\author{
Muhammad Manaqib', Renova Dedi Pantoro ${ }^{2}$ \\ ${ }^{1}$ Program Studi Matematika FST UIN Syarif Hidayatullah Jakarta \\ ${ }^{2}$ Program Studi Matematika FMIPA UNY \\ Email : muhammad.manaqib@uinjkt.ac.id \\ renovadedi@gmail.com
}

\begin{abstract}
Determining the route of the tourism bus to visit some tourism object not only to minimaze the distance, but also there are another purpose, such as minimization cost, maximizing tourism object, minimizing trip time, and maximizing the visit time in the tourism object. But, determining the route we should notice the open hours of the tourism object and operational hours for the tourism bus. The matter of determining the rute that involve some purpuse and considering the visit hours in the math is known as multi-objective vehicle routing problem with times windows. Goal programming is one of technique to solve the model with the multi-objective function and assist to find an optimal solution form several an compatible purpose. The purpose of goal programming is to minimize the total of deviation of all the purpose. Based on the case, goal programming will be apply the multi-objective vehicle routing problem with times windows which has been finised with goal programming approachment. Then, from the model it applied for the trip route of tourism agen Purpledia Pictures T\&T in Bali island. The completion with LINGO, give an optimal route solution of the tourism bus, as many as three route with total cost IDR 1.269.700,00, as 25 tourism object which has been visited from 49 tourism place, the tour time 14.1 hours in 3 days and the total time to visited of tourism object 27 hours in 3 days.
\end{abstract}

Key words : multi-objective vehicle routing problem with time windows, goal programming, trip route, tourism bus.

\section{PENDAHULUAN}

Indonesia adalah salah satu destinasi wisata di dunia, terutama di Bali dengan keindahan alam dan budaya. Banyak pengunjung yang ingin berlibur ke Bali guna mengisi liburan ataupun sekedar jalan-jalan menikmati keindahan Pulau Dewata. Banyak tempat wisata yang menarik untuk dikunjungi di Pulau Bali, dari keindahan alam berupa pantai ataupun bukit dan juga keindahan budaya seperti tari kecak yang sudah mendunia. Namun karena adanya keterbatasan waktu dalam mengunjungi Pulau Bali, maka pada umumnya para pengunjung ingin memaksimalkan kunjungan kebeberapa tempat wisata dengan mengefisienkan waktu kunjung yang ada dan rute kunjungan ke tempat wisata. Selain itu, biro perjalanan wisata sebagai penyedia jasa yang mengantar para wisatawan berwisata juga ingin mengoptimalkan rute perjalanan agar diperoleh keuntungan optimal.

Penentuan rute kendaraan untuk mengunjungi beberapa tempat, dengan tujuan meminimumkan total waktu perjalanan ataupun jarak tempuh yang memenuhi kendala-kendala 
yang diberikan, dalam matematika dikenal dengan masalah penentuan rute kendaraan (Vehicle Routing Problem) (VRP). Penentuan rute perjalanan kendaraan pada kenyataannya tidak hanya sebatas meminimumkan jarak, melainkan terdapat beberapa tujuan yang lain, seperti meminimumkan biaya, memaksimalkan pelanggan yang dilayani, meminimumkan waktu distribusi, dan memaksimalkan kapasitas angkut kendaraan. Masalah penentuan rute yang melibatkan beberapa tujuan, dalam matematika dikenal sebagai vehicle routing problem dengan tujuan ganda (multi-objective).

VRP dengan rute kendaraan dari depot ke himpunan tempat yang tersebar secara geografis, dengan jumlah permintaan diketahui dan kendala kapasitas kendaraan serta time windows yang diberikan, dikenal dengan Vehicle Routing Problem with Time Windows (VRPTW) (Lee dkk, 2003). Kendala time window terdapat pada pelanggan dan juga depot. Time windows pelanggan didefinisikan sebagai interval waktu yang ditentukan pelanggan untuk menerima barang sesuai dengan waktu yang diinginkan dan time window depot didefinisikan sebagai batas waktu kendaraan berangkat dan kembali ke depot.

Tujuan yang akan dicapai dalam penelitian ini adalah

1. membentuk model matematika multiobjective vehicle routing problem with times windows dengan pendekatan goal programming untuk menyelesaikan masalah optimisasi rute perjalanan bus pariwisata.

2. mencari solusi optimal rute perjalanan bus pariwisata di Pulau Bali studi kasus agen wisata Purpledia Pictures T\&T.

Salah satu manfaat dari penelitian ini adalah sebagai bahan masukkan agen wisata di Pulau Bali dalam menentukan rute perjalanan bus wisata.

\section{METODE PENELITIAN}

Penelitian ini menggunakan studi kasus pada agen wisata Purpledia Pictures T\&T untuk penerapan model matematika multi-objective vehicle routing problem with times windows dengan pendekatan goal programming. Agen wisata Purpledia Pictures T\&T merupakan salah satu agen wisata di Pulau Bali, yang melayani tour wisata mengunjungi objek-objek wisata di Pulau Bali. Data yang diambil terkait dengan objek-objek wisata yang ada di Pulau Bali, jam operasional objek wisata, jam operasional bus pariwisata, dan biaya perjalanan. Untuk menemukan solusi yang optimal dari permasalahan tersebut penulis menggunakan bantuan program komputer yaitu program LINGO.

Untuk mencapai tujuan penelitian yang ditetapkan, disusun prosedur penelitian yang ijelaskan pada Gambar 1. 


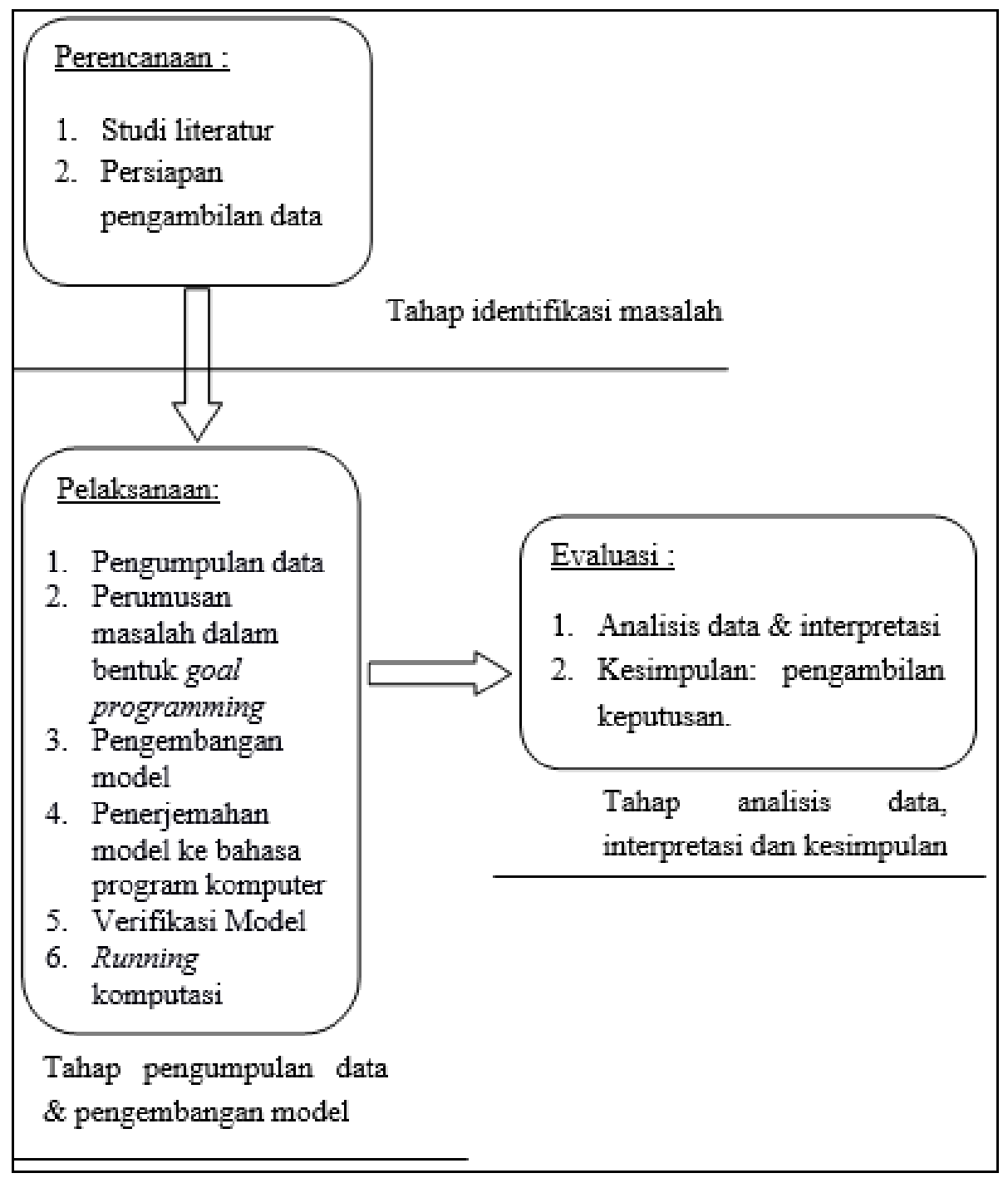

Gambar 1. Diagram Alur Penelitian

\section{HASIL DAN PEMBAHASAN}

\section{Model Matematika Multi-Objective VRPTW dengan Pendekatan Goal Programming}

Model multi-objective VRPTW yang digunakan dalam penelitian ini mengacu model yang dikembangkan Fariborz Jolai dan Mehdi Aghdaghi (2008) dengan beberapa modifikasi untuk menyesuaikan permasalahan perjalan bus pariwisata. Beberapa tujuan yang dirumuskan dalam model multi-objective VRPTW dengan pendekatan goal grogramming ini, meliputi

a. Meminimumkan biaya total perjalanan

b. Memaksimumkan banyaknya tempat yang terkunjungi

c. Meminimumkan total waktu perjalanan

d. Memaksimumkan total waktu kunjungan di tempat wisata.

Rute yang diperoleh harus memenuhi beberapa persyaratan atau kendala yang ada, yaitu: 
a. Setiap tempat hanya dapat dikunjungi satu kali

b. Setiap rute perjalanan berawal dan berakhir di hotel

c. Kekontinuan rute

d. Tidak terdapat subtour pada rute yang di bentuk

e. Total biaya perjalanan tidak melebihi biaya maksimal yang ditentukan

f. Total waktu operasional bus tidak melebihi waktu maksimal yang ditetapkan

g. Jika suatu tempat wisata dapat terkunjungi, maka waktu kedatangan dan kepergian dari tempat wisata harus pada jam operasional.

Berdasarkan formulasi masalah multiobjective VRPTW dengan pendekatan goal programming diatas, maka secara matamatis dapat dibuat model sebagai berikut. Jaringan perjalanan bus dapat direpresentasikan dalam sebuah graf. Simpul mewakili tiap lokasi tempat wisata serta garis berarah sebagai ruas jalan penghubung antar tempat wisata maupun hotel dengan tempat wisata.

Didefinisikan $G\left(N^{\prime}, A\right)$ adalah graf berarah yang mempresentasikan jaringan kunjungan. Didefinisikan

$N=\{1,2, \ldots, n\}$ adalah himpunan tempat wisata,

$N^{\prime}=\{0,1,2, \ldots, n, n+1\}$ adalah himpunan yang anggotanya adalah himpunan $N$ ditambah simpul 0 , dan simpul $n+1$, dengan 0 dan $n+1$ mempresentasikan hotel,

$A=\left\{(i, j): i, j \in N^{\prime}\right\}$,

$a_{i}=$ jam buka tempat wisata $i$,

$b_{i}=$ jam tutup tempat wisata $i$,

$s_{i}=$ durasi kunjungan tempat wisata $i$,

$t_{i j}=$ waktu perjalanan dari $i$ ke $j$,

$c_{i j}=$ biaya perjalanan dari $i$ ke $j$,

$R=\{1,2, \ldots, k\}$ adalah himpunan rute rendaraan,

$T R_{k}=$ total waktu perjalanan rute $k$,

$B_{k}=$ total biaya perjalanan rute $k$,

$U C=$ biaya perjalanan maksimal,

$U T=$ waktu perjalanan maksimal,

$W K M=$ minimal total waktu kunjungan $\mathrm{di}$ tempat wisata.

Selanjutnya didefinisikan variabel keputusan $x_{i j}^{k}=\{1$, terdapat perjalanan i ke j pada rute $k$

$\{0$, tidak ada perjalanan i ke j pada rute $k$

$y_{i}^{k}=\left\{\begin{array}{l}1, \text { i dikunjungi pada rute } k \\ 0, \text { i tidak dikunjungi pada rute } k\end{array}\right.$

$w_{i}^{k}=$ waktu sampai di tepat wisata $i$ pada rute

$k$.

Didefinisikan variabel simpangan

$d_{1}^{+}=$simpangan positif tujuan pertama,

$d^{-}=\{0$, jika pelanggan i dapat terlayani

$d_{2 i}^{-}=\{1$, jika pelanggan i tidak terlayani.

$d_{3}^{+}=$simpangan positif tujuan ketiga

$d_{4}^{-}=$simpangaan negatif tujuan keempat.

Setelah semua variabel didefinisikan

maka dibentuklah model matematika multi-

objective VRPTW yang dirumuskan dalam

bentuk goal programming. Berikut model matematika multi-objective VRPTW dengan pendekatan goal programming.

1. Fungsi Tujuan

Meminimumkan

$Z=d_{1}^{+}+\sum_{i \in N} d_{2 i}^{-}+d_{3}^{+}+d_{4}^{-}$.

2. Kendala Tujuan

a. Meminimumkan biaya perjalanan

$\left(\sum_{k \in R} B_{k}\right)-d_{1}^{+}=0$

dengan

$B_{k}=\sum_{(i, j) \in A} c_{i j} \cdot x_{i j}^{k}, \quad \forall k \in R$

b. Memaksimalkan banyaknya tempat wiasata yang dikunjungi

$\sum_{k \in R} y_{i}^{k}+d_{2}^{-}=1, \quad \forall i \in N$

c. Meminimumkan total waktu perjalanan

$\sum_{k \in R} T R_{k}-d_{3}^{+}=0$

dengan

$T R_{k}=\sum_{i \in 0 \cup N} \sum_{j \in N \cup n+1} t_{i j} x_{i j}^{k} \quad \forall k \in R$

d. Memaksimalkan total waktu kunjungan di tempat wisata

$d_{4}^{-}=W K M-\sum_{k \in R} W K_{k}$

3. Kendala Struktural 
a. Setiap tempat wisata hanya dapat dikunjungi tepat satu kali

$$
\sum_{j \in N^{\prime}} x_{i j}^{k}=y_{i}^{k}, \quad \forall i \in N^{\prime}, \forall k \in R
$$

b. Setiap rute perjalanan kendaraan berawal dan berakhir di hotel

$$
\sum_{j \in N} x_{0 j}^{k}=1, \quad \forall k \in R
$$

c. Kekontinuan rute

$$
\begin{aligned}
& \sum_{i \in 0 \cup N} x_{i r}^{k}-\sum_{j \in N \cup n+1} x_{r j}^{k}=0, \\
& \forall i \in N \quad, \forall k \in R
\end{aligned}
$$

d. Tidak terdapat subrute pada rute yang dibentuk

$$
\begin{aligned}
& w_{i}^{k}+s_{i}+t_{i j}-M\left(1-x_{i j}^{k}\right) \leq w_{j}^{k}, \\
& \forall i, j \in N^{\prime}, \forall k \in R
\end{aligned}
$$

e. Total biaya perjalanan tidak melebihi biaya maksimal yang ditetapkan

$$
\sum_{k \in R} B_{k} \leq U C
$$

f. Total waktu operasional bus kurang dari waktu operasional maksimal yang ditetapkan.

$$
\sum_{k \in R} T R_{k} \leq U T
$$

g. Jika suatu tempat wisata dapat terkunjungi maka waktu kedatangan dan kepergian dari tempat wisata harus pada jam operasional tempat wisata tersebut.

$$
a_{i} \leq w_{i}^{k} \leq b_{i}-s_{i}, \forall i \in N, \forall k \in R
$$

\section{Optimisasi Rute Perjalanan Bus Pariwisata di Pulau Bali \\ a. Perumusan Masalah}

Purpledia Picture T\&T adalah salah satu agent wisata di Pulau Bali yang meruupakan sebuah biro jasa yang memberikan panduan bagi wisatawan untuk berkunjung di Bali. Selain itu juga memberikan pelayanan terhadap konsumen berupa fasilitas penjemputan dan tempat tinggal. Purpledia Picture T\&T melayani kunjungan wisata di 49 tempat wisata di Pulau Bali. Akan tetapi, agen wisata juga memiliki keterbatasan waktu, jam operasional kendaraan, dan biaya transportasi.
Agen wisata Purpledia Pictures T\&T membagi tempat wisata di Pulau Bali menjadi tiga wilayah. Ketiga wilayah tersebut adalah Bali Selatan, Bali Timur Tengah dan Bali Utara, selengkapnya terdapat pada Tabel 1 . Setiap kendaran memiliki waktu operasional 15 jam setiap hari di mulai dari pukul 07:00 WITA sampai 22.00 WITA, dan biaya bahan bakar setiap harinya maksimal Rp. 850.000,00 yang telah ditetapkan oleh agen wisata. Selain itu ditetapkan total waktu kunjungan di tempat wisata setiap harinya minimal selama 8 jam.

Penyelesaian masalah tersebut dapat dilakukan dengan pengoptimalan rute yang digunakan. Rute yang diperoleh diharapkan dapat meminimumkan biaya total perjalanan, memaksimumkan banyaknya tempat wisata yang dikunjungi, meminimumkan total waktu perjalanan, dan memaksimumkan total waktu kunjungan di tempat wisata. Yang dimaksut biaya perjalanan adalah biaya bahan bakar yang diperlukan untuk pengantaran wisatawan. Waktu perjalanan adalah waktu bus berjalan yang diperlukan untuk mengunjungi sejumlah tempat wisata. Waktu kunjungan adalah lama wisatawan di tempat wisata.

Rute yang diperoleh juga harus memenuhi beberapa hal sebagai berikut:

1) Setiap tempat wisata hanya dapat dikunjungi tepat satu kali.

2) Setiap rute perjalanan kendaraan berawal dan berakhir di hotel.

3) Kekontinuan rute yaitu jika suatu kendaraan mengunjungi tempat wisata maka setelah melayani akan meninggalkan tempat wisata tersebut.

4) Tidak terdapat subtour pada rute yang dibentuk.

5) Total biaya perjalanan tidak melebihi $\mathrm{Rp}$ $850.000,00$.

6) Total waktu operasional bus tidak melebihi 15 jam.

7) Total waktu wisata/berkunjung di Bali adalah 3 hari, dalam 1 hari akan mengunjungi 1 wilayah yang ada (Bali bagian selatan, Bali timur bagian tengah, atau Bali bagian utara).

8) Jika suatu tempat wisata dapat terkunjungi maka waktu kedatangan dan kepergian dari 
tempat wisata harus pada jam operasional tempat wisata tersebut.

\section{b. Pengumpulan Data}

Berikut diberikan beberapa data dalam penelitian ini.

1. Daftar tempat wisata di Pulau Bali.

Setiap tempat wisata akan diberi simbol dengan angka dan hotel tempat menginap disimbolkan dengan angka 0 dan $n+1$.

2. Data jarak dan waktu tempuh antar tempat wisata.

Perhitungan jarak dan waktu perjalanan antar tempat wisata diperoleh dengan bantuan Google Map, dan dipilih jarak tempuh yang paling minimal.

3. Data biaya perjalanan antar tempat wisata. Biaya perjalanan dalam penelitian ini adalah sebatas biaya bahan bakar bus yang dibutuhkan untuk menempuh suatu jarak. Perhitungan yang digunakan adalah setiap bus pariwisata memerlukan satu liter BBM (jenis solar) setiap menempuh $2 \mathrm{~km}$ atau setiap $1 \mathrm{~km}$ memerlukan $1 / 2$ liter BBM. Harga 1 liter BBM di SPBU per April 2017 adalah $\mathrm{Rp} 5.150,00$, maka setiap perjalan 1 $\mathrm{km}$ membutukan biaya perjalanan $\mathrm{Rp}$ $2.575,00$. Perhitungan biaya perjalanan antar tempat wisata dapat diperoleh dengan mengalikan jarak antar tempat wisata dengan Rp 2.575,00. Biaya bahan bakar setiap harinya yang ditetapkan oleh agen wisata maksimal sebesar Rp. 850.000,00.

4. Data times windows

Setiap kendaran memiliki waktu operasional 15 jam setiap hari di mulai dari pukul 07:00 WITA sampai 22.00 WITA. Data tentang jam buka dan tutup tempat wisata selanjunya dikonversi dalam rentang 0 sampai 24, dengan pukul 07.00 WITA sebagai titik awalnya.

Tabel 1.Data Durasi Kunjungan, Jam Buka $\left(a_{i}\right)$ dan Jam Tutup $\left(b_{i}\right)$ Tempat Wisata

\begin{tabular}{llccc}
\hline No & \multicolumn{1}{c}{ Tempat } & $\boldsymbol{a}_{\boldsymbol{i}}$ & $\boldsymbol{b}_{\boldsymbol{i}}$ & Durasi Kunjung \\
\hline 1. & Kuta (Hotel) & 0 & 15 & \\
\hline & BALI SELATAN & 2 & 13 & 1 Jam \\
\hline 1. & Alas Kedaton & 2 & 11 & 1 Jam \\
2. & Butterfly Park & 0 & 22 & 1 Jam \\
3. & Legian & 3 & 11 & 2 Jam \\
4. & Lempuyang Agung & 1,5 & 9,5 & 1 Jam \\
5. & Museum Bali & 2,5 & 10,5 & 1 Jam \\
6. & Bajra Sandi & 1 & 11 & 1 Jam \\
7. & Nusa Dua & 1 & 13 & 2 Jam \\
8. & Pantai Dreamland & 0 & 12 & 2 Jam \\
9. & Pantai Balangan & 0 & 17 & 2 Jam \\
10. & Pantai Jimbaran & 0 & 12 & 2 Jam \\
11. & Pantai Pandawa & 2 & 14 & 1 Jam \\
12. & GWK & 3 & 10 & 2 Jam \\
13. & Tanjung Benoa & 1 & 13 & 1 Jam \\
14. & Tanah Lot & 2 & 12 & 1 Jam \\
15. & Taman Ayun & 2 & 12 & 1 Jam \\
16. & Uluwatu & & & \\
\hline & Bali Timur Tengah & 1 & 12 & 2 Jam \\
\hline 1. & Ubud & 0 & 12 & 2 Jam \\
2. & Sukawati & 1 & 13 & 1 Jam \\
3. & MAS & 1 & 13 & 1 Jam \\
4. & Celuk & 3 & 11 & 1 Jam \\
5. & Besakih & 0 & 13 & 1 Jam \\
6. & Amed & 2 & & 1 Jam \\
7. & Batu Bulan & & & \\
& & & 13 &
\end{tabular}




\begin{tabular}{clccc} 
8. & Kintamani & 0 & 13 & 1 Jam \\
9. & Tegallalang & 1 & 11 & 1 Jam \\
10. & Tenganan & 2 & 12 & 1 Jam \\
11. & Tulamben & 1 & 13 & 1 Jam \\
12. & Bukit Jambul & 2 & 12 & 1 Jam \\
13. & Taman Soekasada & 2 & 11 & 1 Jam \\
14. & Tembuku & 1 & 11 & 1 Jam \\
15. & Candidasa & 2 & 12 & 1 Jam \\
16. & Kubu & 2 & 11 & 1 Jam \\
17. & Tirta Gangga & 0 & 12 & 1 Jam \\
18. & Pura Tirta Empul & 1 & 11 & 1 Jam \\
19. & Goa Gajah & 2 & 11 & 1 Jam \\
20. & Pura Goa Lawah & 1 & 13 & 1 Jam \\
21. & Taman Nusa & 3 & 11 & 1 Jam \\
22. & Kerthagosa & 2 & 11 & 1 Jam \\
23. & Tampak Siring & 3 & 11 & 1 Jam \\
\hline & Bali Utara & & & 1 Jam \\
\hline 1. & Air Terjun Git-Git & 2 & 10 & 1 Jam \\
2. & Nung-Nung & 2 & 11 & 1 Jam \\
3. & Art Center & 1,5 & 9,5 & 1 Jam \\
4. & Sekumpul & 2 & 11 & 1 Jam \\
5. & Danau Beratan & 12 & 1 Jam \\
6. & Jatiluwih & 13 & 1 Jam \\
7. & Terunyan & 2 & 11 & 2 Jam Jam \\
8. & Air Terjun Les & 3 & 11 & \\
9. & Lovina & 2 & 10 & \\
10. & Menjangan & 2 & & \\
\hline
\end{tabular}

\section{Model Matematika}

Berdasarkan rumusan masalah tersebut, masalah penentuan rute wisata agen wisata Purpledia Pictures T\&T dapat dimodelkan dalam model matematika multi-objective VRPTW dengan pendekatan goal programming. Model matematika penentuan rute wisata tersebut dibuat berdasarkan model matematika multi-objective VRPTW dengan pendekatan goal programming yang telah dijelaskan sebelumnya dan data dari hasil pengolahan. Model matematika dalam masalah ini dibuat untuk setiap wialayah.

\section{Penyelesaian Masalah Rute Kunjungan Tempat Wisata Di Pulau Bali}

Model Matematika multi-objective VRPTW dengan pendekatan goal programming untuk setiap kendaraan kemudian diselesaikan menggunakan software LINGO untuk mendapatkan solusi berupa rute dengan banyaknya biaya perjalanan, banyaknya tempat wisata yang terkunjungi, waktu perjalanan, dan waktu kunjungan. Berikut ditampilkan dalam bentuk flowchart penyelesaian menggunakan LINGO. 


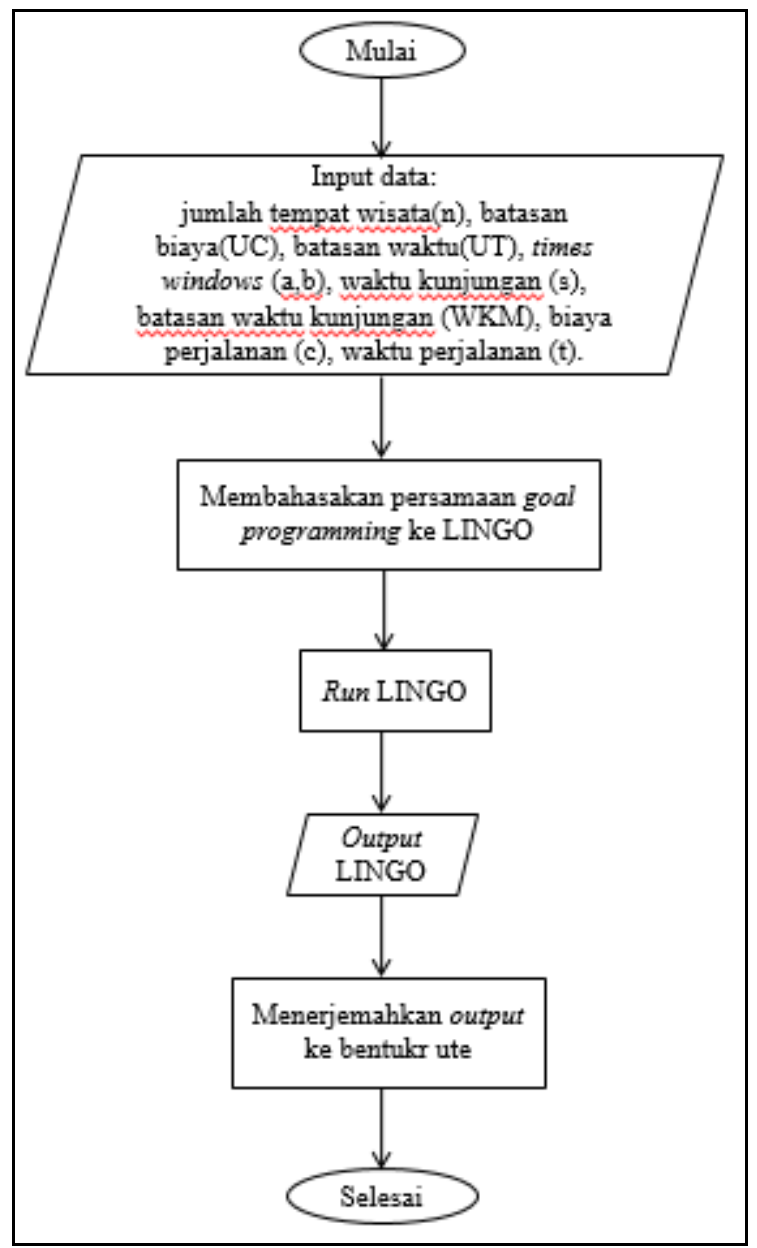

Gambar 2. Flowchart Penyelesaian LINGO

Penyelesaian menggunakan LINGO diperoleh 3 rute optimal untuk setiap wilayah di Pulau Bali. Rute optimal kunjungan ke tempat wisata di Pulau Bali bagian Selatan Agen Wisata Purpledia Pictures T\&T adalah Hotel Pantai Jimbaran - GWK - Uluwatu - Nusa Dua - Museum Bali - Monumen Braja Sandi Taman Ayu - Alas Kedaton - Tanah Lot Legian - Hotel. Sebanyak 10 tempat wisata dari 16 tempat wisata yang terdapat di Bali Selatan dapat dikunjungi. Total biaya perjalanan $\mathrm{Rp} 347.500,00$, total waktu perjalanan bus 3,33 jam, sedangkan lama waktu berkunjung di tempat wisata selama $11 \mathrm{jam}$.
Rute optimal kunjungan ke tempat wisata di Pulau Bali bagian Timur Tengah Agen Wisata Purpledia Pictures T\&T adalah Hotel Celuk - Kerthagosa - Pura Goa Lawah - Goa Gajah - Pura Tirta Empul - Tegalalang Tampak Siring - MAS - Batu Bulan - Hotel. Sebanyak 9 tempat wisata dari 23 tempat wisata yang terdapat di Bali Selatan dapat dikunjungi. Total biaya perjalanan $\mathrm{Rp} 334.000,00$, total waktu perjalanan bus 3,26 jam, sedangkan lama waktu berkunjung di tempat wisata selama 9 jam.

Rute optimal kunjungan ke tempat wisata di Pulau Bali bagian utara Agen Wisata Purpledia Pictures T\&T adalah Hotel - Art 
Center - Air Terjun Sekumpul - Lovina - GitGit - Beratan - Jati Luwih - Hotel. Sebanyak 9 tempat wisata dari 23 tempat wisata yang terdapat di Bali utara dapat dikunjungi. Total biaya perjalanan $\mathrm{Rp} 588.200,00$, total waktu perjalanan bus 7.51 jam, sedangkan lama waktu berkunjung di tempat wisata selama 7 jam.

\section{KESIMPULAN}

Berdasarkan pembahasan diatas maka dapat disimpulkan

1. Diperoleh model matematika multi-objective vehicle routing problem with time windows yang diselesaikan dengan pendekatan goal programming yang mengoptimalkan empat tujuan yaitu meminimumkan biaya perjalanan, memaksimalkan tempat kunjungan, meminimumkan waktu perjalanan, dan memaksimalkan waktu kunjungan wisata.

2. Diperoleh solusi rute optimal perjalanan wisata sebanyak 3 rute dengan total biaya perjalanan Rp. 1.269.700,00, sebanyak 25 tempat wisata terkunjungi dari 49 tempat wisata yang ada dengan waktu perjalanan 14.1 jam dalam 3 hari, serta dapat dimaksimalkan waktu total kunjungan tempat wisata 27 jam dalam 3 hari.

\section{DAFTAR KEPUSTAKAAN}

Azi, dkk. 2006. An Exact Algorithm for SingleVehicle Routing Problem with Time Windows and Multiple Routes .European Journal of Operational Research 178(2007) 755-766.

Calvente, Herminia, dkk. 2004. Vehicle Routing Problem with Soft Time Windows : An Optimization Based Approach. Monografías del Seminario Matemático García de Galdeano 31, 295-304 (2004).
Eka V. 2011. Pendekatan Goal Programming untuk Penentuan Rute Kendaraan pada Kegiatan Distribusi. Hasil Penelitian. FMIPA: ITS

Fariborz J and Mehdi A. 2008 . A Goal Programming Model for Single Vehicle Routing Problem with Multiple Routes . Journal of Industrial and Systems Engineering Vol. 2, No. 2, pp 154-163, Summer 2008.

Garsede, Anissa K. dan Nyimas. 2010. Perencanaan Distribusi LPG dengan Periodic Vehicle Routing Problem guna Minimasi biaya Transportasi. Jurnal Performa Vol. 9 No. 1, hal 29 - 38.

Golden B. 2008. The Vehicle Routing Problem: Latest Advances and New Challenges. New York: Springer.

Hillier F dan Lieberman G. 2001. Introduction to Operations Research Seventh Edition, New York: McGraw-Hill.

Joubert. 2007. The Vehicle Routing Prolem: Origins and Variants. Hasil penelitian: University of Pretoria.

Luenberger, David G. dan Yinyu . 2008. Linear and Non Linear Programming Third Edition. New York: Springer.

Patricia B. 2008. Scatter Search for Vehicle Routing Problem with Time Windows and Split Deliveries. Hasil Penelitian. Departmen of Production Egineering: University of Sao Paulo.

Taha, Hamdy A. 2007. Operations Research: An Introduction Eighth Edition. New Jersey: Pearson Prentice Hall.

Takes F. 2010. Applying Monte Carlo Techniques to the Capacitated Vehicle Routing Prolem. Master Thesis: Leiden University.

Watanabe S. dan Sakakibarata K. 2007. A Multiobjectivization Approach for Vehicle Routing Problem. Hasil penelitian: Mororan Institute of Tecnology : Ritsumeikan University. 